\title{
Ramipril reduced mortality and cardiovascular morbidity in high risk adults
}

The Heart Outcomes Prevention Evaluation Study Investigators. Effects of an angiotensin-converting-enzyme inhibitor, ramipril, on death from cardiovascular causes, myocardial infarction, and stroke in high-risk patients. N Engl J Med 2000 Jan 20;342:145-53.

QUESTION: In adults who are at high risk for cardiovascular (CV) events, does ramipril, an angiotensin converting enzyme (ACE) inhibitor, reduce CV events? (Vitamin E results will be reported separately.)

\section{Design}

Randomised \{allocation concealed*\}†, blinded (patients, clinicians, and outcome assessors), ${ }^{*}$ controlled $2 \times 2$ factorial design trial with planned interim analyses (Heart Outcomes Prevention Evaluation [HOPE] study).

\section{Setting}

161 centres in North America, 76 in 14 western European countries, and 30 in Argentina and Brazil.

\section{Participants}

9541 adults (mean age 66 y, 73\% men) who were aged $\geq 55$ years and had a history of coronary artery disease, stroke, peripheral vascular disease, or diabetes and $\geq 1$ other $\mathrm{CV}$ risk factor. Exclusion criteria were heart failure, ejection fraction $<0.4$, use of an ACE inhibitor, uncontrolled hypertension, nephropathy, or myocardial infarction (MI) or stroke. Follow up was $>99.9 \%$

\section{Intervention}

Adults were allocated to ramipril, $2.5 \mathrm{mg} / \mathrm{d}$ for 1 week, $5 \mathrm{mg} / \mathrm{d}$ for 3 weeks, then $10 \mathrm{mg} / \mathrm{d}(\mathrm{n}=4645)$, or to placebo $(\mathrm{n}=4652)$.

\section{Main outcome measures}

MI, stroke, and CV mortality.

\section{Main results}

The study was stopped early. Adults in the ramipril group had lower rates of combined MI, stroke, or CV mortality; MI; stroke; CV mortality; all cause mortality ( $\mathrm{p}$ for all comparisons $\leq 0.006$ ) (table); revascularisation procedures $(16 \%$ v $18 \%, \mathrm{p}<0.002)$; cardiac arrest $(0.8 \%$ $v 1.3 \%, \mathrm{p}=0.02)$; heart failure $(9 \% v 12 \%, \mathrm{p}<0.001)$; and complications related to diabetes $(6 \% v 8 \%, \mathrm{p}=0.03)$ than did adults in the placebo group.

\section{Conclusion}

Ramipril reduced mortality and cardiovascular morbidity in adults at high risk for cardiovascular events.

* See glossary.

$\uparrow$ The HOPE Study Investigators. Can J Cardiol 1996;12:127-37.

\section{COMMENTARY}

Over the past decade, several studies have documented that ACE inhibitors reduce all cause mortality and probably CV morbidity in patients with left ventricular dysfunction and congestive heart failure. The HOPE study was designed to assess whether ACE inhibitors may also prevent CV events in a broader spectrum of high risk patients. This hypothesis was convincingly confirmed regardless of left ventricular function. Benefit was found across all subgroups and was additive to other therapies with proven secondary preventive effects. Furthermore, the preventive effect was beyond that expected from blood pressure lowering. The findings strongly support a direct $\mathrm{CV}$ protective effect of ramipril.

Of interest, patients with diabetes had the same relative benefit as patients without diabetes, despite the fact that the investigators had not required established CV disease for inclusion of the patients with diabetes. This finding strengthens the hypothesis that patients with diabetes should receive active preventive therapies. In a recent metaanalysis, Golan and colleagues ${ }^{1}$ argued that treating all middle aged patients with type 2 diabetes with ACE inhibitors on the basis of the protective effects on the kidneys alone would be cost effective. Considering the HOPE study results, this strategy is even more justified. The $30 \%$ reduction in new onset diabetes is also important but needs to be confirmed. Ramipril was easy to introduce and often well tolerated. Direct treatment costs will certainly increase as ACE inhibitors are used more often. However, the HOPE study may also provide the basis for savings, for example, through fewer echocardiographic screening tests of left ventricular function after MI and fewer revascularisations.

In the light of available evidence, we recommend that al middle aged patients with either established CV disease or diabetes and 1 additional risk factor (which almost all middle aged patients with diabetes have) should be considered for treatment with ACE inhibitors.

Klas Malmberg, MD Lars Rydén, MD Karolinska Hospital Stockholm, Sweden

1 Golan L, Birkmeyer JD, Welch HG. Ann Intern Med 1999;131:660-7.
Sources of funding: Medical Research Council of Canada; Hoechst-Marion Roussel:AstraZeneca, King Pharmaceuticals; Natural Source Vitamin E Association and Neoma: Heart and Stroke Foundation of Ontario.

For correspondence: Dr S Yusuf, Canadian Cardiovascular Collaboration Project Office, Hamilton General Hospital, 237 Barton Street East, Hamilton, Ontario L8L 2X2, Canada. Fax +1905521 1166.

Ramipril v placebo for adults at high risk for cardiovascular (CV) events:

\begin{tabular}{lrrll} 
Outcomes at mean 4 y & Ramipril & Placebo & RRR (95\% Cl) & NNT (CI) \\
MI, stroke, or CV mortality & $14 \%$ & $18 \%$ & $22 \%(14$ to 30$)$ & 26 (19 to 43$)$ \\
\hline CV mortality & $6 \%$ & $8 \%$ & $26 \%(13$ to 36$)$ & $50(33$ to 105$)$ \\
\hline Ml & $10 \%$ & $12 \%$ & $20 \%(10$ to 30$)$ & $42(27$ to 89$)$ \\
\hline Stroke & $3 \%$ & $5 \%$ & $32 \%(16$ to 44$)$ & 67 (43 to 145$)$ \\
\hline All cause mortality & $10 \%$ & $12 \%$ & $16 \%(5$ to 25$)$ & 56 (32 to 195$)$ \\
\hline$\neq C V$ = cardiovascular; $\mathrm{MI}=$ myocardial infarction. Other abbreviations defined in glossary; RRR, NNT, and Cl
\end{tabular}
provided by authors. 